\title{
Status of pre-processing of waste electrical and electronic equipment in Germany and its influence on the recovery of gold
}

\author{
Perrine Chancerel, Til Bolland and Vera Susanne Rotter
}

\begin{abstract}
Waste electrical and electronic equipment (WEEE) contains gold in low but from an environmental and economic point of view relevant concentration. After collection, WEEE is pre-processed in order to generate appropriate material fractions that are sent to the subsequent end-processing stages (recovery, reuse or disposal). The goal of this research is to quantify the overall recovery rates of pre-processing technologies used in Germany for the reference year 2007. To achieve this goal, facilities operating in Germany were listed and classified according to the technology they apply. Information on their processing capacity was gathered by evaluating statistical databases. Based on a literature review of experimental results for gold recovery rates of different pre-processing technologies, the German overall recovery rate of gold at the pre-processing level was quantified depending on the characteristics of the treated WEEE. The results reveal that - depending on the equipment groups - pre-processing recovery rates of gold of 29 to $61 \%$ are achieved in Germany. Some practical recommendations to reduce the losses during pre-processing could be formulated. Defining mass-based recovery targets in the legislation does not set incentives to recover trace elements. Instead, the priorities for recycling could be defined based on other parameters like the environmental impacts of the materials. The implementation of measures to reduce the gold losses would also improve the recovery of several other non-ferrous metals like tin, nickel, and palladium.
\end{abstract}

\section{Keywords}

Waste electrical and electronic equipment (WEEE), e-waste, recycling, precious metals, resource recovery

Date received: 28 July 2009; accepted: 8 March 2010

\section{Introduction}

Various definitions of 'Waste electrical and electronic equipment' (WEEE), also called e-waste or e-scrap, can be found in the literature (Widmer et al., 2005). WEEE is defined in the WEEE Directive as 'electrical and electronic equipment' (EEE) which is waste, including all components, subassemblies and consumables which are part of the product at the time of discarding. Huisman et al. (2007) pointed out that WEEE is a particularly complex waste flow in terms of:

- the variety of products,

- the association of different materials and components,

- the concentration of hazardous substances, and

- the growth patterns of this waste stream which can be influenced not only by need but also by changes in technology, design and marketing.
UNEP (2005) reported that 20 to 50 million tonnes of WEEE are generated worldwide every year. The total quantity of WEEE produced in Germany was evaluated between 3.5 and $12.3 \mathrm{~kg} \mathrm{capita}^{-1}$ year $^{-1}$ (Chancerel 2010). Huisman et al. (2007) reported that the generation of household WEEE in Europe could grow annually at between 2.5 and $2.7 \%$.

Precious metals (gold, silver and the platinum-group metals platinum, palladium, rhodium, ruthenium, iridium

Institute of Environmental Technology, Technische Universität Berlin, Berlin, Germany.

\section{Corresponding author:}

Perrine Chancerel, Institute of Environmental Technology, Technische Universität Berlin, Sekr. Z2, Strasse des 17. Juni 135, 10623 Berlin, Germany

Email: chancereldut.tu-berlin.de 
Table 1. Comparison of recovery rates of precious metals in material streams suitable for precious metal recovery after the pre-processing

\begin{tabular}{|c|c|c|c|c|c|}
\hline Reference & Process description & Input & Silver & Gold & Palladium \\
\hline Meskers et al. 2009 & $\begin{array}{l}\text { Manual dismantling } \\
\text { (step one) }\end{array}$ & 1.4 tonne of $P C$ & $49 \%$ & $80 \%$ & $66 \%$ \\
\hline Meskers et al. 2009 & $\begin{array}{l}\text { Manual dismantling } \\
\text { (steps one and two) }\end{array}$ & 1.4 tonne of $P C$ & $92 \%$ & $97 \%$ & $99 \%$ \\
\hline Meskers et al. 2009 & $\begin{array}{l}\text { Manual depollution and } \\
\text { smashing and hand } \\
\text { picking, hammer mill } \\
\text { and automating sorting } \\
\text { automatic sorting }\end{array}$ & 1.4 tonne of $P C$ & $75 \%$ & $70 \%$ & $41 \%$ \\
\hline Chancerel et al. 2009 & $\begin{array}{l}\text { Manual depollution } \\
\text { and shredding and } \\
\text { automatic sorting }\end{array}$ & $\begin{array}{l}27 \text { tonnes of IT and } \\
\text { consumer equipment }\end{array}$ & $11 \%$ & $26 \%$ & $26 \%$ \\
\hline Chancerel and Rotter 2008 & Manual dismantling & $\begin{array}{l}176 \mathrm{~kg} \text { of IT and con- } \\
\text { sumer equipment }\end{array}$ & - & $\approx 90 \%$ & - \\
\hline Van Schaik and Reuter 2009 & Shredding and sorting & Not indicated & - & $\approx 15 \%$ & - \\
\hline
\end{tabular}

and osmium) are used for manufacturing 'electrical and electronic equipment' (EEE) because of their properties, for instance high resistance to oxidation and corrosion and high conductivity. Especially gold, palladium, and silver are widely used in printed circuit boards (PCB) as a component of complex material mixtures (Hagelüken 2006). The economic relevance of precious metals in WEEE was emphasized by Hagelüken (2006), Koehnlechner (2008), Malhotra (1985) and Streicher-Porte et al. (2005), and their environmental impacts by Huisman et al. (2007). Huisman (2004) revealed that three-quarters of the environmental impacts of the materials contained in mobile phones result from the gold and palladium content. Additionally, the increasing scarcity of these trace elements is putting new challenges on the recycling of WEEE.

WEEE management can be divided into the following steps: (1) collection, (2) pre-processing, (3) recovery, reuse and/or disposal of WEEE. As the first step of the treatment, pre-processing determines to which recovery or disposal processes the materials are fed (Chancerel et al., 2009). Despite the variety of material fractions and specifications for end-processing, five major recovery routes for material recycling can be identified: plastics recycling, ferrous recycling, aluminium recycling, copper and precious metal recycling. The latter may include the recovery of some base and special metals in the case of integrated metal smelters.

One task of pre-processing is to ensure that materials enter the appropriate recovery processes. Pre-processing can be carried out manually (manual disassembly), mechanically (for example material shredding and automatic sorting) or with processes combining manual and mechanical technologies. The technology used for pre-processing influences the mechanical properties of the liberated materials in the output and thus the further separation steps. Cui and Forssberg (2003) presented automatic sorting technologies that can be found in pre-processing facilities. Gmünder (2007), Willems et al. (2006) and Zhang and Forssberg (1998) discussed the advantages and limitations of applying and combining the different technologies.

The recovery of precious metals from collected WEEE begins with the separation of printed circuit boards during pre-processing. The printed circuit boards coming from pre-processing can either be intact (for example if the WEEE was manually dismantled) or shredded, which often leads to a dispersion of precious metals (Chancerel et al., 2009). The trade-off of losing some valuable materials to recover other materials is described by Hagelüken (2006). During pre-processing of WEEE, the so-called graderecovery function applies (Hagelüken, 2006). The recovery of a specific material (for example a metal) from an input stream decreases with increasing purity requirements of that material separated into an output fraction. Therefore, the optimum operating conditions for pre-processing are a compromise between grade (quality) and recovery (quantity) (Chancerel et al., 2009). The grade-recovery function applies specifically to trace elements like precious metals, because some printed circuit boards or other parts containing precious metals end up in side-streams like plastics or ferrous metals that are not set up for precious metal recovery (Hagelüken, 2006).

Table 1 summarizes the experimental results of precious metal recovery rates of different WEEE pre-processing technologies published by various researchers. Chancerel and Rotter (2008) investigated a manual dismantling process and estimated that around $82 \%$ of the gold contained in IT and consumer equipment is sent to precious-metals recovery processes. The remaining gold is either sent to further mechanical pre-processing or sent to processes that are not able to recover it (for example plastic recycling) and thus is lost. The results have the same order of magnitude as the 
Table 2. Groups of equipment considered in this investigation

\begin{tabular}{lll}
\hline Group & $\begin{array}{l}\text { No. of different } \\
\text { equipment types } \\
\text { belonging to } \\
\text { the group }\end{array}$ & Examples of equipment \\
\hline Mobile telephone & 1 & \\
$\begin{array}{l}\text { Desktop personal computer } \\
\text { CRT monitor }\end{array}$ & 1 & Includes the drives, excludes the monitors \\
$\begin{array}{l}\text { Larger high-grade equipment } \\
\text { Smaller high-grade equipment }\end{array}$ & 12 & Cathode-ray-tube computer monitors, TV sets \\
Low-grade equipment & 26 & DVD player, video game console, computer LCD monitor, notebook \\
& & GPS, digital camera, MP3 player \\
Total & 55 & Vacuum cleaner, wall clock, radio control vehicle, electrical drill, \\
\end{tabular}

results of Meskers et al. (2009), who investigated only the manual dismantling of personal computers. Chancerel et al. (2009) showed that around $24 \%$ of the containing gold could be recovered after the pre-processing in a German facility using a shredding technology combined with manual processes. Meskers et al. (2009) conducted similar experimental investigations in a facility using a different liberation technology ('smasher' device) for personal computers. Much higher recovery rates $(70 \%)$ were determined by Meskers et al. (2009) as compared with the results of Chancerel et al. (2009), probably due to the use of a different liberation technology and the homogeneity of the input material (only desktop personal computers) compared to the complex input mix considered by Chancerel et al. (2009). Van Schaik and Reuter (2009) mentioned recovery rates of $15 \%$ for gold in a shredding facility but did not provide the detailed experimental setup and results.

The literature review showed that quite low recovery rates for precious metals are achieved by the pre-processing technologies applied currently. The recovery rates during pre-processing do not only depend on the used technology, but also on the characteristics of the input WEEE. The efficiency of pre-processing affects the overall recovery of precious metals from WEEE. Therefore, the recovery of precious metals during pre-processing of WEEE needs to be improved. The objectives of this research are to inventory the applied technologies for pre-processing WEEE in Germany and to quantify the overall gold recovery rates at the pre-processing level for the reference year 2007. This approach allows a better understanding of the whole system, to identify reasons for resource losses and to give recommendations for improvement.

\section{Materials and methods}

This article focuses on the pre-processing of small WEEE (sWEEE) as the sum of WEEE belonging to categories 'small household appliances', 'IT and telecommunications equipment', 'consumer equipment', 'electrical and electronic tools' and 'toys, leisure and sports equipment' of Annex IA of the WEEE Directive. The flows of gold contained in sWEEE pre-processed in Germany in 2007 are investigated. The sWEEE at the collection and at the end-processing level, as well as the sWEEE exported to other countries, are not considered. For this study, the sWEEE was classified in six equipment groups according to their function and their expected gold content (Table 2). This classification implies the assumption that similar pre-processing technologies are applied to the equipment types of the same group.

For the calculation of the recovery rate for precious metal, an inventory of the pre-treatment facilities plants operating in Germany was created. Therefore, information on the (1) number of pre-processing facilities for WEEE in Germany in 2007, (2) technology used for pre-processing and (3) quantity of WEEE treated in 2007, as well as (4) the classification of the treated WEEE according to the categories defined in the WEEE Directive, have been collected from the following sources.

- Publications from German industry associations, namely associations of EEE manufacturers (ZVEI and BITKOM), associations of the waste management industry (bvse, BDE and VKS) and the association of the workshops for physically disabled persons (GDW gGmbH).

- A survey via e-mail of companies operating facilities where WEEE is pre-processed.

- Annual waste statistics from the Federal Statistical Office (destatis) and the statistical offices of the German states.

- Databases on waste treatment of the environmental agencies of the German states.

The outcome of the data collection varied, depending on the sources of data. The majority of the industry associations do not publish data on the exact number of WEEE pre-processing facilities operating in 2007 and on the applied technologies. Concerning the survey via email, 24 companies were contacted, of which six answered the questionnaire, which contained five questions about the specifications of 
Table 3. Exemplary overview of the data gathered through the questionnaires

\begin{tabular}{llllllll}
\hline & \multirow{2}{*}{$\begin{array}{l}\text { Input } \\
\text { (tonnes year }\end{array}$} & \multicolumn{2}{l}{ Distribution of the input over the collection groups (Mass. \%) } & \multicolumn{2}{c}{$\begin{array}{l}\text { Pre-processing } \\
\text { technology }\end{array}$} \\
\cline { 3 - 8 } & 1 & 2 & 3 & 4 & 5 & Manual \\
\hline Facility 1 & 2500 & 0 & 25 & 50 & 10 & 15 & Mechanical 2 \\
Facility 2 & 12000 & 30 & 10 & 30 & 0 & $\ldots$ & $\ldots$ \\
$\ldots$ & $\ldots$ & $\ldots$ & $\ldots$ & $\ldots$ & $\ldots$ & $\ldots$ & $\ldots$ \\
\hline
\end{tabular}

the input of the treatment facilities and the applied pre-processing technology. Table 3 presents exemplarily the information gathered through the questionnaires. Because of the small number of respondents and, therefore, their limited representativeness, the answers of the six companies could not be further evaluated.

Annual waste statistics from the Federal Statistical Office (destatis) and the statistical offices of the German states usually contain data on pre-processing facilities for all types of waste of the European List of Waste. However, this list does not distinguish between the different categories of WEEE as defined in the WEEE directive. Therefore, the data was of no help for this investigation. The databases on waste preprocessing of the environmental agencies of the German states provide data with very variable quality. The most valuable source of data on number of facilities, quantity and types of treated WEEE, and applied technologies was the 'Entsorgungsatlas' ('Disposal Atlas') of the German State of North Rhine-Westfalia (NRW). Due to the lack of further information, the data contained in this database (AIDA, 2009) was extrapolated to the national level (Germany).

The inventory of facilities operating in Germany presented in the previous chapter was used to determine the distribution of the sWEEE over the pre-processing technologies $\left(x_{i, j}\right)$. The gold recovery rates achieved by the different pre-processing technologies $\left(R_{i, j}\right)$ were determined based on the results of the experimental investigations in preprocessing facilities presented in the literature review. These investigations are snapshots limited to a certain facility at a certain time for a certain input material. They have a limited representativeness but are the only available data.

The recovery rate for gold is defined as the mass of gold recovered divided by the mass of gold contained in the input sWEEE. To determine the overall German recovery rates for gold at the pre-processing level for the six equipment groups defined in Table 2, the percentage of each sWEEE fraction reaching a particular pre-processing technology is multiplied by the specific recovery rate achieved by this technology. That means that following formula is applied:

$$
R_{i}=\sum_{j=1}^{n} x_{i, j} \times R_{i, j}
$$

where $R_{i}$ is the total recovery rate in Germany for equipment group $i$ at the pre-processing level; $R_{i, j}$ is the recovery rate achieved by pre-processing technology $j$ for equipment group I; $x_{i, j}$ is the fraction of the sWEEE belonging to equipment group $i$ treated by the pre-processing technology $j$ $\left(\sum_{j=1}^{n} x_{i, j}=1\right)$.

Without the specification of the uncertainty, measurement results cannot be compared with each other or with reference values (German pre-standard DIN V ENV 13005). The uncertainty is the doubt about a result, namely an evaluation of its quality and accuracy.

The parameter 'standard deviation' (square root of the variance), also expressed as 'variation coefficient' (standard deviation divided by the value of the result), was selected to quantify the uncertainty of the results. If the standard deviation of data from the literature was not available, the variation coefficient had to be estimated.

\section{Results}

\section{Operating facilities for pre-processing of sWEEE}

The database AIDA (2009) revealed that about 32 (pre-) treatment facilities for WEEE were operating in NRW in 2007, treating about 39000 tonnes of WEEE. Three-quarters of these facilities dismantle the WEEE manually, whereas the remaining eight facilities apply mechanical technologies like shredding (Figure 1). However, the mechanical facilities have a much larger processing capacity and treat around three-quarters of the WEEE arriving to the pre-processing facilities in NRW.

For a more detailed analysis, Bolland (2009) classified the pre-processing facilities in AIDA by their technology into the following categories.

- Manual: manual pre-processing (dismantling) only. However, in practice some parts rich in precious metals, like power supplies or computer drives and some low-grade equipment, are not manually dismantled but sent to other facilities for mechanical treatment.

- Mechanical 1: selective treatment according to Annex II of the WEEE-Directive of the European Union and automated mechanical pre-processing.

- Mechanical 2: selective treatment according to the WEEE-Directive as a combination of manual and mechanical pre-processing. In some facilities of type 'Mechanical 2', selected equipment types like 


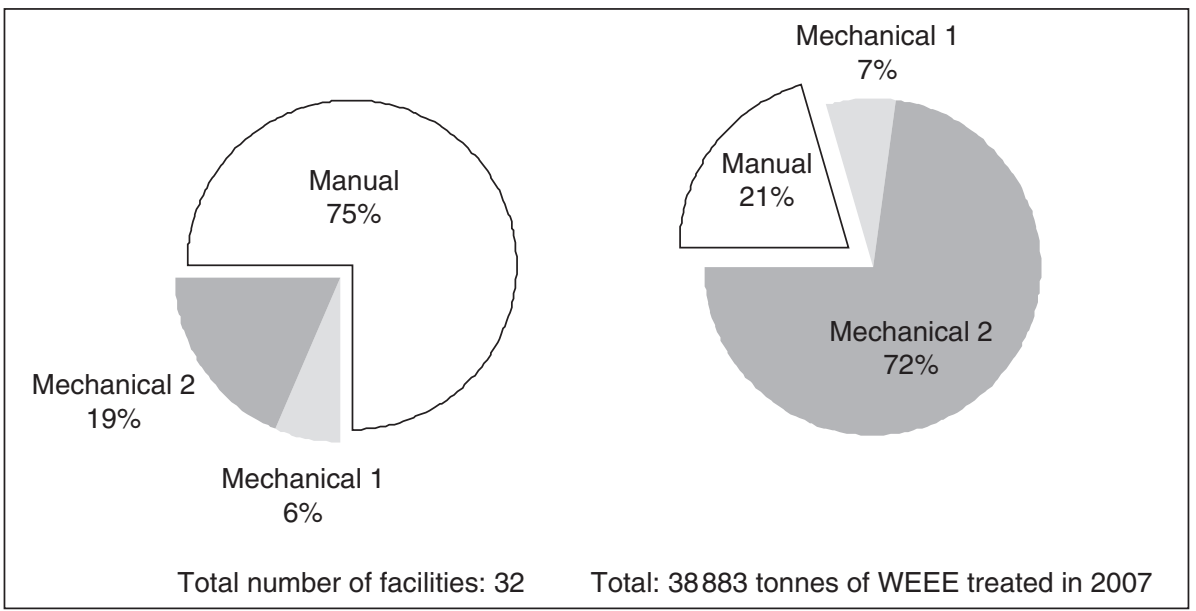

Figure 1. Distribution of applied technologies for pre-processing WEEE according to the number of facilities and the nominal pre-processing capacity in the federal state of North Rhine-Westphalia in 2007 (AIDA 2009).

Table 4. Distribution of the WEEE belonging to the collection groups 3 and 5 over the different pre-processing technologies in Germany in 2007

\begin{tabular}{lll}
\hline $\begin{array}{l}\text { Applied } \\
\text { technology }\end{array}$ & $\begin{array}{l}\text { Collection group 3 IT, } \\
\text { telecommunication and } \\
\text { consumer equipment }\end{array}$ & $\begin{array}{l}\text { Collection group 5 } \\
\text { Small household } \\
\text { equipment, } \\
\text { tools and toys }\end{array}$ \\
\hline Manual & $24 \%$ & $26 \%$ \\
Mechanical 1 & $0 \%$ & $25 \%$ \\
Mechanical 2 & $76 \%$ & $49 \%$ \\
Total & $100 \%$ & $100 \%$ \\
\hline
\end{tabular}

personal computers or CRT monitors are dismantled manually.

- The option of no pre-processing, where small high-grade equipment like mobile phones after manual removal of the battery are fed as complete devices into a recovery process for precious metals, is also considered.

Based on the data provided by the database AIDA (2009), the distribution of the sWEEE over the different pre-processing technologies could be differentiated according to the collection groups as defined by the German implementation of the WEEE Directive (the ElektroG). Table 4 presents the distribution of the sWEEE belonging to collection group 3 (IT and consumer equipment) and collection group 5 (small household equipment, tools and toys) over the different treatment technologies.

On average, $76 \%$ by mass of the sWEEE of collection group 3 (IT and consumer equipment) was treated with a technology of type 'mechanical 2', whereas the remaining $24 \%$ was pre-processed manually. Regarding collection group 5 (small household equipment, tools and toys), 26\% of the WEEE was pre-processed manually, $25 \%$ in facilities of type 'mechanical 1 ' and $49 \%$ in facilities of type 'mechanical 2'. This distribution of the WEEE over the different pre-treatment technology in NRW was assumed to be representative for the rest of Germany in 2007.

\section{Recovery rates for pre-processing in Germany}

Based on the data of Table 4, the distribution of the sWEEE over the four pre-processing technologies applied in Germany in 2007 was determined (Table 5). Table 5 also presents the assumptions on the recovery rates for precious metals achieved by the pre-processing technologies.

The assumptions on the recovery rates achieved by the different pre-processing technologies are based on a literature review of experimental trials in pre-processing facilities summarized in Table 1. Pre-processing through manual dismantling allows the recovery of $90 \%$ of the gold. Because personal computers are sometimes dismantled manually in facilities of type 'mechanical 2', and considering the results of Meskers et al. (2009), an average recovery rate of 50\% was assumed. Regarding CRT monitors, in Germany the printed circuit boards are usually removed manually (Bolland, 2009). Afterwards, the PCBs of CRT monitors are usually treated mechanically to separate the iron and the aluminium from the precious metals and the copper-rich materials. This mechanical treatment of $\mathrm{PCB}$ leads to losses of precious metals that were, so far, not quantified by experimental investigations. An overall recovery rate for gold from CRT monitors of $60 \%$ was assumed.

The results show that depending on the equipment groups, 29 to $61 \%$ of the gold contained in sWEEE was sent to further end-processing where the gold is recovered. This measurement, for 2007, shows that the potential for future improvement is great. A weak correlation can be recognized between high gold concentration in the WEEE (for example in mobile phones and personal computers) and high recovery rates of the pre-processing technologies 
Table 5. Recovery rates for gold achieved in 2007 by the pre-processing technologies used for pre-processing sWEEE in Germany

\begin{tabular}{|c|c|c|c|c|c|c|c|c|}
\hline \multirow[b]{2}{*}{ Pre-processing type } & \multicolumn{4}{|c|}{ Distribution of the sWEEE over the technologies } & \multicolumn{3}{|c|}{$\begin{array}{l}\text { Recovery rate achieved } \\
\text { by the technologies }\end{array}$} & \multirow{2}{*}{$\begin{array}{l}\text { Total recovery } \\
\text { rate of } \\
\text { pre-processing }\end{array}$} \\
\hline & No PP & Manual & Mech. 1 & Mech. 2 & Manual & Mech. 1 & Mech. 2 & \\
\hline Mobile telephone & $40 \%$ & $10 \%$ & & $50 \%$ & $90 \%$ & & $24 \%$ & $61 \% \pm 6 \%$ \\
\hline $\begin{array}{l}\text { Desktop personal } \\
\text { computer }\end{array}$ & & $24 \%$ & & $76 \%$ & $90 \%$ & & $50 \%$ & $60 \% \pm 6 \%$ \\
\hline CRT monitor & & $24 \%$ & & $76 \%$ & $60 \%^{a}$ & & $60 \%{ }^{a}$ & $60 \% \pm 6 \%$ \\
\hline $\begin{array}{l}\text { Larger high-grade } \\
\text { equipment }\end{array}$ & & $24 \%$ & & $76 \%$ & $90 \%$ & & $24 \%$ & $40 \% \pm 4 \%$ \\
\hline $\begin{array}{l}\text { Smaller high-grade } \\
\text { equipment }\end{array}$ & & $24 \%$ & & $76 \%$ & $90 \%$ & & $24 \%$ & $40 \% \pm 4 \%$ \\
\hline Low-grade equipment & & $26 \%$ & $25 \%$ & $49 \%$ & $50 \%$ & $15 \%$ & $24 \%$ & $29 \% \pm 3 \%$ \\
\hline
\end{tabular}

ancluding mechanical pre-processing of the separated printed circuit boards.

${ }^{b}$ The uncertainty is quantified as standard deviation of the result.

PP, pre-processing; Mech., mechanical.

used in Germany. The high losses of precious metals caused by pre-processing of type 'mechanical 1' partly explain why this technology is mainly used for low-grade equipment. However, the pre-processing technologies currently applied do not set a clear priority on recovering the precious metals of the equipment types that contain higher concentrations of precious metals.

Concerning the uncertainties, data are very scarce. Chancerel et al. (2009) determined that the recovery rate for gold in a pre-processing facility was $24.5 \pm 3.2 \%$. The uncertainty of $3.2 \%$ can be assumed to be the double of the standard deviation (assuming a normal distribution). Thus, if the standard deviation is $1.6 \%$, the variation coefficient is around $6 \%$. This uncertainty does not consider issues relative to the representativeness of the input waste. As all the data and assumptions used to determine the recovery rates are associated with uncertainties and due to the lack of quantitative information on these uncertainties, a rough estimation of the uncertainty was therefore necessary. It was assumed that the variation coefficient of the recovery rates is $10 \%$, which delivers the standard deviations presented in Table 5.

\section{Discussion}

\section{Assessment of the results}

Detailed information on substance flows is needed for a systematic improvement of the recovery of resources from waste flows, considering that the recovery rates depend both on the characteristics of the input and on the technology used, as shown in Table 5. In Germany, no organization systematically collects data on the applied pre-processing technologies on a national level, also not in the frame of the monitoring of waste flows specified in the WEEE directive. This systematic data collection was conducted in Austria by Tesar and
Öhlinger (2009). The lack of transparency in the management system for WEEE in Germany and its consequences were also reported by Leonhardt (2007) and Faulstich and Baron (2008). Some efforts are made at state level, like the development of the AIDA database giving a complete overview of the facilities, the applied technologies and quantitative data on treated waste types. This information needs to be expanded and deepened, to cover the whole country and to address more specific waste types. So far the linkage of the mass flows related to WEEE and substance specific information such as precious metals flows can only be made on the basis of extrapolation of singular investigations. This requires in particular more experimental trials at process level to provide data required for analyses at the macroscopic level (Chancerel et al., 2009). Despite the lack of data and the high uncertainties, the rough assessment of the substance flows presented in this article shows the relevance of the issue and the necessity to develop adequate structures to collect data systematically, supporting a better understanding of the substance flows in the system.

\section{Recommendations to improve the recovery rates for precious metals}

The recovery of gold needs to be improved along the whole chain of WEEE management processes. This includes, for example, collecting more WEEE, since currently a large amount of WEEE is disposed of instead of being recycled (Chancerel, 2010), and avoiding illegal exports to developing countries, where the applied recycling processes have serious negative environmental impacts (Sepúlveda et al., 2010) and cause the loss of valuable resources (Keller, 2006).

In particular, the results showed that the mixed treatment of heterogeneous WEEE in terms of size and material composition leads to sub-optimal recovery rates for precious metals. 
Pre-sorting of end-of-life equipment (also called triage) is recommended not only to separate the devices for reuse, but also to feed the WEEE in adequate treatment processes in order to improve metal-specific recovery rates. Pre-sorting requires knowing the content of precious metals in the different equipment groups and considering this information during the design and the operation of pre-processing facilities. Pre-sorting of sWEEE is facilitated by a careful transport from the collection site to the pre-processing facilities, since it is easier to identify and sort entire devices than broken parts. In practice, questions on the feasibility and practical implementation of pre-sorting still need to be answered. Pre-sorting at municipal collection sites often lacks appropriate space and qualified personnel. Pre-sorting at the pre-processing facility is not viable if the waste equipment already broke during collection and transport. Another option is the set-up of individual collection schemes for small and high-grade equipment, for example through retailer take back systems. This option seems appropriate in term of ensuring high qualitative recycling but also faces limitations because of the logistic challenges and the actual German legal framework. The WEEE legislation of the European Union left the member states free to organise the collection. In Germany, the collection takes place under municipal responsibility. The municipalities collect WEEE in five collection groups addressing more the function of equipment rather then their chemical-physical properties (see also Chancerel et al., 2009).

Additionally, depending on the characteristics of the WEEE of the different equipment groups, some recommendations regarding treatment, for instance pre-processing, can be formulated. Huisman (2004) compared various end-of-life treatment options for mobile phones. He showed that, for both economic and environmental reasons, it is preferable to feed these devices directly into a pyrometallurgical process for recovery of several non-ferrous metals after removal of the battery (without further pre-processing). This applies also to other small high-grade devices like MP3-players and digital cameras.

For larger appliances, such as personal computers which are very rich in precious metals, a manual removal of the printed circuit boards or the application of technologies that prevent the uncontrolled dispersion of the precious metals over different material fractions are recommended. Chancerel et al. (2009) showed that the shredding of WEEE and the automatic sorting of the PCB cause losses of precious metals through dispersion over the output fractions. A technical solution could be to practise a negative sorting of materials containing precious metals by removing, after liberation, the materials that clearly contain no precious metals (for example plastic casings, ferrous metals) and considering the remaining material as possibly containing precious metals. From a design perspective, the accessibility of PCB is key to high separation efficiency and has to be improved for the future.
Regarding low-grade sWEEE, in which precious metals contribute to a small fraction of the environmental impacts (Huisman et al., 2007), the applied pre-processing technology should consider the precious metals, even though it should primarily focus on the management of the most relevant materials.

The ability of the applied technology to recover the precious metals and other substances should be experimentally monitored periodically, using a method similar to the method described by Chancerel et al. (2009). Moreover, research should be encouraged to develop new technologies able to recover the precious metals in the different equipment mixes more efficiently.

\section{Recommendations for policy-making}

The mass-oriented recovery targets defined by the WEEE Directive set incentives to apply processes that allow the recovery of the most mass-relevant materials, for instance ferrous metals and plastics. As shown by Chancerel et al. (2009), Huisman et al. (2007), Reuter et al. (2005) and Schill (2007), the recovery targets of the WEEE Directive do not encourage the recovery of trace materials. The precious metals contained in trace concentrations in the materials sent to recovery processes for plastics and ferrous metals are usually not recovered (Chancerel et al., 2009), so that the loss of trace metals is a trade-off for the maximization of the recovery of mass-relevant materials. The efforts to improve the recovery of gold would also improve the recovery of other trace metals such as tin, nickel, and palladium (Chancerel, 2010).

Nevertheless, setting recycling priorities requires clearly a better understanding of the overall benefits of recycling and recovery. Other theoretical approaches to define recycling priorities are suggested, depending on the following factors.

- The environmental impacts of the materials contained in the waste, which can be measured for example by using 'total material requirement' (TMR) as an indicator developed by the Wuppertal Institute (Ritthoff et al., 2002), 'environmental value' (Huisman, 2003) or 'Fraunhofer IZM Toxic Potential Indicator' (Middendorf et al., 2000)

- Economic criteria, by aiming at recovering the materials that bring the highest economic revenues.

Shirahase et al. (2007) provided a comparison of different weighting methods for quantifying the recovery priority of metals contained in printed circuit boards, considering the amount of reserves, the amount of production, the prices and other parameters relating to the different metals.

It has to be noted that the above-mentioned approaches only weigh the potential material impact on the basis of primary production but not impacts of the recovery process itself. A full environmental life-cycle impact assessment is necessary to come to a more holistic assessment. 
Considering the above mentioned arguments, the development of recycling standards, as recommended by the European Commission (COM, 2005), would help promoting efficient recycling technologies able to deal with the numerous challenges related with the recovery of resources and the environmental-sound disposal of hazardous substances contained in WEEE. As emphasized by Leroy (2008), 'law is not the most appropriate instrument to promote state-of-the-art treatment and recycling technologies, or, worse, to lay down specific operational requirements, e.g. "manual dismantling",. By the time law enters into force, new and better techniques have made it to the market. The definition of standards should be accompanied by control measures, to make sure that the recommended technologies are really used in practice. These control measures could be combined with the collection of data relating to the substance flows at the industrial facilities.

\section{Conclusion}

This research showed that information about the use of technologies for the pre-processing of WEEE is not monitored and available at national level in Germany. Regional data had to be upscaled, which leads to high uncertainties of the results. For a more strategic planning of raw material recovery, it is essential to know the precious metal concentration in different types of WEEE and the specific recovery rates of pre-processing technologies.

The specific conclusions of this research are listed here.

- For mobile phones and computers, the $60 \%$ recovery rate for gold at the pre-processing level is higher in comparison with other equipment types, but considering the total content of gold in these two equipment types, $40 \%$ are significant losses.

- There is a trend of using more mechanical processing for lower grade equipment (household equipments and tools), resulting in lower gold recovery rates.

- For high grade equipment other than computers and mobile phones, the pre-processing infrastructure is currently not sufficiently able to deal with inherent value in economic and environmental terms.

One key to improve the recovery of gold during pre-processing of WEEE is a good separation of the PCB. This can be achieved by appropriate design, by pre-sorting of WEEE according to their material composition and by implementing more selective size reduction technologies.

\section{Acknowledgement}

The authors thank the Deutsche Bundesstiftung Umwelt (DBU) for providing financial support through the Scholarship Programme.

\section{References}

AIDA (2009) Informationsplattform Abfall in NRW [Information platform Waste in North Rhine-Westfalia]. From NRW Ministry for Environment and Nature Protection, Agriculture and Consumer Protection: http://www.nrw-luawebapps.de/aida/ (accessed 24 July 2009).

Bolland $\mathrm{T}$ (2009) Erstbehandlungsanlagen für Elektro- und Elektronikaltgeräte - eine Stoffstromanalyse [First treatment facilities for WEEE - a material flow analysis]. Diploma thesis, Technische Universität Berlin. Berlin, Germany.

Chancerel P (2010) Substance Flow Analysis of the Recycling of Small Waste Electrical And Electronic Equipment - An Assessment of the Recovery of Gold and Palladium. Doctoral thesis, Technische Universität Berlin, Göttingen, Germany: Cuvillier Verlag.

Chancerel P, Rotter VS (2008) Stoffstromanalyse und Modellierung von mechanischen Aufbereitungsprozessen für Elektro- und Elektronikaltgeräte [Substance flow analysis and modeling of mechanical pre-processing for waste electrical and electronic equipment]. In: Proc. of Abfallforschungstage. Göttingen, Germany.

Chancerel P, Meskers CEM, Hagelüken C, and Rotter VS (2009) Assessment of precious metal flows during pre-processing of waste electrical and electronic equipment. Journal of Industrial Ecology 13: $791-810$

COM (Commission of the European Communities) (2005) Taking sustainable use of resources forward: A Thematic Strategy on the prevention and recycling of waste. $\mathrm{COM}(2005)$ 666. Commission of the European Communities, Brussels, Belgium.

Cui J, Forssberg E (2003) Mechanical recycling of waste electric and electronic equipment: a review. Journal of Hazardous Materials B99: 243-263.

Faulstich M, Baron M (2008) Abfallwirtschaft in Deutschland 2008 [Waste management in Germany in 2008]. Müllhandbuch Band 1, article 0148.01

Gmünder S (2007) Recycling - From Waste to Resource - Assessment of Optimal Manual Dismantling Depth of a Desktop PC in China Based on Eco-efficiency Calculations. Diploma thesis, Eidgenössische Technische Hochschule Zürich, Zürich, Switzerland.

Hagelüken C (2006) Improving metal returns and eco-efficiency in electronics recycling - a holistic approach for interface optimisation between pre-processing and integrated metals smelting and refining. In: Proceedings of the IEEE International Symposium on Electronics \& the Environment, 811 May 2006, San Francisco, USA, pp. 218-223, IEEE: Scottsdale, AZ, USA.

Huisman J (2003) The QWERTY/EE concept, Quantifying Recyclability and Eco-Efficiency for End-of-Life Treatment of Consumer Electronic Products. Doctoral thesis, Delft University of Technology, Delft, the Netherlands.

Huisman J (2004) QWERTY and Eco-Efficiency Analysis on Cellular Phone Treatment in Sweden. The Eco-efficiency of the Direct Smelter Route versus Mandatory Disassembly of Printed Circuit Boards. Stockholm, Sweden.

Huisman J, Magalini F, Kuehr R, Maurer C, Delgado C, Artim E, and Stevels ALN (2007) 2008 Review of Directive 2002/96 on Waste Electrical and Electronic Equipment (WEEE). Bonn, Germany: United Nations University.

Keller M (2006) Assessment of Gold Recovery Processes in Bangalore, India and Evaluation of an Alternative Recycling Path for Printed Wiring Boards. Diploma thesis, Eidgenössische Technische Hochschule Zürich, Zürich, Switzerland.

Koehnlechner R (2008) E-waste in Canada - Gold Diggers in E-Waste. Recycling Magazin 18: 6-11.

Leonhardt E (2007) Geregelte Verantwortungslosigkeit? Erfahrungen mit der Produktverantwortung bei Elektro(nik)-Geräten aus Sicht eines Umweltund Verbraucherschutzverbandes [Regulated irresponsibility? Experience with producer responsibility for EEE from the perspective of an association for environmental and consumer protection]. Deutsche Umwelthilfe: www.ssl.duh.de/1141.html (accessed 28 July 2009). 
Leroy P (2008) Necessary harmony - Request for European Standards for WEEE treatment. Opinion. Recycling Magazine 13, 16-17: www.recyclingmagazin.de/rmeng (accessed 5 April 2009).

Malhotra SC (1985) Trends and opportunities in electronic scrap reclamation. Conservation \& Recycling 8: 327-333.

Meskers CEM, Hagelüken C, Salhofer S, and Spitzbart M. (2009) Impact of pre-processing routes on precious metal recovery from PCs. In: Proc. of European Metallurgical Conference EMC 2009, 28 June-1 July 2009, Innsbruck, Austria, Clausthal Zellerfeld, Germany: GDMB Verlag.

Middendorf A, Nissen NF, Griese H, Müller J, Pötter H, Reichl H, and Stobbe I. (2000) The EE-Toolbox - a modular assessment system for the environmental optimisation of electronics. In; Proc. of the 2000 IEEE International Symposium on Electronics and the Environment, 8-10 May 2000, San Francisco, USA, IEEE: Denver, CO, USA.

Reuter MA, Boin UMJ, Van Schaik A, Verhoef E, Heiskanen K, Yang $\mathrm{Y}$, and Georgalli G (2005) The Metrics of Material and Metal Ecology: Harmonizing the Resource, Technology and Environmental Cycles. Amsterdam, The Netherlands: Elsevier Science.

Ritthoff M, Rohn H, and Liedtke C (2002) Calculating MIPS: Resource Productivity of Products and Services. Wuppertal, Germany: Wuppertal Institute for Climate, Environment and Energy, Report Wuppertal Spezial 27e.

Schill W-P (2007) Incentives for Precious Metals Recycling in German WEEE Legislation - Strategies for Implementing Individual Producer Responsibility. Diploma thesis, Technische Universität Berlin. Berlin, Germany.

Sepúlveda A, Schluep M, Renaud FG, Streicher M, Kuehr R, Hagelüken C, and Gerecke AC (2010) A review of the environmental fate and effects of hazardous substances released from electrical and electronic equipments during recycling: Examples from China and India. Environmental Impact Assessment Review 30: 28-41.

Shirahase T, Kida A, and Murakami S (2007) Understanding the flows of metals in waste PC. In: Proc. of the Fourth NIES Workshop on E-waste, Tsukuba, Japan, 15-20, Tsukuba, Japan: NIES.

Streicher-Porte M, Widmer R, Jain A, Bader HP, Scheidegger R, and Kytzia S (2005) Key drivers of the e-scrap recycling system: Assessing and modelling e-scrap processing in the informal sector in Delhi. Environmental Impact Assessment Review 25: 472-491.

Tesar M, Öhlinger A (2009) Elektroaltgerätebehandlung in Österreich Zustandsbericht 2008 [WEEE treatment in Austria - Status 2008]. Bundesministeriums für Land- und Forstwirtschaft, Umwelt und Wasserwirtschaft. Vienna, Austria.

UNEP (United Nations Environment Programme) (2005) E-waste, the hidden side of IT equipment's manufacturing and use. Environment Alert Bulletin 5. http://www.grid.unep.ch/product/publication/download/ew_ewaste.en.pdf "www.grid.unep.ch/product/publication/ download/ew_ewaste.en.pdf" (accessed 24 March 2010).

Van Schaik A, Reuter MA (2009) Modellhaftes Recycling [Model-like recycling]. Recycling Magazin 04: 26-29.

Widmer R, Oswald-Krapf H, Sinha-Khetriwal D, Schnellmann M, and Böni H (2005) Global perspectives on e-scrap. Environmental Impact Assessment Review 25: 436-458.

Willems B, Dewulf W, and Duflou JR (2006) Can large-scale disassembly be profitable? A linear programming approach to quantifying the turning point to make disassembly economically viable. International Journal of Production Research 44: 1125-1146.

Zhang S, Forssberg E (1998) Mechanical recycling of electronics scrap the current status and prospects. Waste Management \& Research 16: $119-128$. 